Research Article

\title{
Investigation on Triaxial Dynamic Model Based on the Energy Theory of Bedding Coal Rock under Triaxial Impact Compression
}

\author{
Yang Xue $\mathbb{D}^{1},,^{1,2}$ Xiaohui Liu $\left.\mathbb{D}\right)^{1,2,3}$ Rui Zhao $\mathbb{D}^{1,2}$ Yu Zheng $\mathbb{D}^{1,2}$ and Xin Gui $\mathbb{D}^{1,2}$ \\ ${ }^{1}$ Key Laboratory of Fluid and Power Machinery (Xihua University), Ministry of Education, Chengdu 610039, China \\ ${ }^{2}$ School of Energy and Power Engineering, Xihua University, Chengdu 610039, China \\ ${ }^{3}$ Key Laboratory of Deep Earth Science and Engineering (Sichuan University), Ministry of Education, Chengdu 610065, China
}

Correspondence should be addressed to Rui Zhao; zrcc118@mail.xhu.edu.cn

Received 18 January 2021; Accepted 22 July 2021; Published 3 August 2021

Academic Editor: Zhixiong Li

Copyright (C) 2021 Yang Xue et al. This is an open access article distributed under the Creative Commons Attribution License, which permits unrestricted use, distribution, and reproduction in any medium, provided the original work is properly cited.

To investigate the dynamic failure characteristics of bedding rocks in depth, a series of dynamic impact compression tests on parallel and vertical bedding coal rocks were conducted by the split Hopkinson pressure bar test system at $10-10^{3} \mathrm{~s}^{-1}$ strain rates and $0,4,8$, and $12 \mathrm{MPa}$ confining pressures. According to the experiments, the mechanical properties and energy characteristics of bedding coal rock under different confining pressures and strain rates were obtained, and a triaxial dynamic constitutive model of bedding coal rock was established based on the energy theory of rock failure. The results show that the compressive strength, peak strain, incident energy, dissipated energy, and dynamic strength increase factor gradually increase with increase in strain rate, but the increase in peak strain weakens as confining pressure rises. The influence of bedding structure on strength and energy is not obvious in the uniaxial state, while it gradually enhances as confining pressure increases. The obvious difference in DIF and the energy dissipation ratio of bedding coal rocks gets obvious in SHPB tests. Considering the influence of confining pressure, strain rate, and bedding on the dynamic failure characteristics, the dynamic constitutive model of bedding coal rock was established by introducing the comprehensive influence factor $K$ and the DIF. Comparing with test results, the model parameters are almost confirmed, and the correctness of the model is further verified by analysing the law of $K$ value. Meanwhile, the stress-softening characteristics of coal rock in postpeak are well simulated by the dynamic constitutive model. The results can provide reference value for dynamic issues such as high-efficiency rock breaking, prevention of rock burst, and surrounding rock support in deep rock masses.

\section{Introduction}

Bedding is the main manifestations of metamorphic rocks and sedimentary rocks [1-3]. The changes in the mechanical properties of rock caused by these discontinuous structural planes (bedding) have important impact on engineering. Under static strain rate loading (less than $10^{1} \mathrm{~s}^{-1}$ ), the bedding direction is closely related to the mechanical properties of rock, where the obvious anisotropy is shown in terms of strength and deformation [4-9]. In recent years, rock bursts and other dynamic disasters have been induced by dynamic loads such as excavation, drilling, and blasting in underground engineering, and the dynamic failure characteristics of layered rocks have attracted much attention $[10,11]$. The study of coal rock failure laws under the action of explosive shock waves is always a hot topic in the fields of geophysics and rock engineering $[2,11-13]$.

The split Hopkinson pressure bar test system is an important test technique for studying the dynamic failure characteristics of rocks, and layered rocks are comprehensively studied by SHPB. Duan performed SHPB impact compression tests on the layered sedimentary rock where the loading direction was perpendicular to bedding plane [14], indicating that the cementation of layer interface does not significantly cause the attenuation of the stress wave but is important for the dynamic response and failure mode of the layered sedimentary rock. Qiu et al. [15], Zhang et al. [16], Wu et al. [17], and Wen et al. [18] have conducted uniaxial impact compression tests on layered rocks (including sandstone, slate, crystalline rock, and artificial layered 
composite rock) by the SHPB system. Their research shows that the strength, failure strain, and elastic modulus of layered rocks change nonlinearly with the increase in bedding angles, and the failure modes vary with different bedding angles. As we all know, rock is a typical strain ratedependent material [19-21]. Thus, as the strain rate increases, the nonlinear characteristics due to different bedding angles become more obvious [17]. Liu et al. [9] further discussed the energy release characteristics of layered rocks during uniaxial impact compression tests and found that the energy dissipation of vertical bedding coal rocks is greater than that of parallel bedding under the same degree of damage. Han et al. [22] confirmed that under the uniaxial impact compression tests of artificially prefabricated jointed rock, the energy transmission coefficient and the growth rate of elastic strain energy reduced, and the damage becomes more complicated due to the discontinuous medium structural surface. The energy coefficient has a nonlinear relationship with the bedding angles in the uniaxial impact compression tests, and larger angle will cause larger energy reflection coefficient and smaller energy transfer coefficient [23]. Although many research studies have been achieved progress in the dynamic failure of layered rocks under uniaxial compression, there are few studies under triaxial confining pressure. In the triaxial impact compression test, Yang et al. [24] determined that the compressive strength, peak strain, and elastic modulus of shale were affected by bedding angles under the confining pressure effect. The peak stress of shale increases linearly with increase in confining pressure, and the strain rate shows obvious confining pressure enhancement effect. Therefore, it is necessary to conduct triaxial dynamic impact tests on layered rocks for further investigating the dynamic failure characteristics of layered rocks under deep stress conditions.

Based on experimental analysis and theoretical research studies on layered rocks, lots of dynamic constitutive models have been proposed. Wang et al. [25] established an elastoplastic constitutive model of transversely isotropic rock based on elastic mechanics and generalized plastic mechanics. Li et al. [26] developed a dynamic compression model of discontinuous rock mass based on Hooke, improved Saint-Venant, and Newton elements, but application of the model is restricted by determining 8 model parameters. Li [27] and Liu et al. [28] established damage constitutive models of jointed rock masses, respectively, where the impact of macroscopic and mesoscopic rock mass defect on rock failure is considered. Considering the strain rate effects and bedding dip angles, Ou et al. [29] established a dynamic compression constitutive model of slate by introducing a bedding damage element model. Sun and Zhang [30] established a dynamic constitutive model of shale which considered the coupling effect of bedding structure and load. Based on fractal theory, the roughness of rock discontinuities described by fractal dimensions is used to establish a joint fractal damage model of a single jointed rock [31]. However, due to the limitation in the laboratory experiment of layered rock, the current dynamic constitutive models of layered rock are almost suitable for uniaxial compression, without considering the confining pressure effect. The dynamic failure characteristics of layered rocks can be better mastered with the establishment of a triaxial dynamic constitutive model in bedding coal rock, which is beneficial to the exploitation of deep rock resources.

In order to provide reference value for dynamic issues such as high-efficiency rock breaking, rock burst prevention, and surrounding rock support of deep rock masses, impact compression tests on vertical and parallel bedding coals were conducted to explore their dynamic failure characteristics under different strain rates and confining pressures. Based on energy theory, a triaxial dynamic constitutive model of bedding coal rocks was established by considering the effects of bedding, strain rate, and confining pressure, which can better exhibit the essence of rock failure.

\section{SHPB Test}

2.1. Material Preparation. The experimental materials were taken from the 2\# coal seam of Furong Baijiao Coal Mine, Yibin City, Sichuan Province, China, with a buried depth of $300 \sim 450 \mathrm{~m}$. Furong Baijiao coal mainly consists of carbon, oxygen, and silicon, and it belongs to sulfur-rich anthracite. The differences of typical coal rock in surface morphology and structure were compared in the same magnification of the scanning electron microscope. The magnification coefficients are, respectively, 100, 500, 1500, and 3000, which are shown in Figure 1. As can be seen from Figure 1, there are straight and wavy stripes on the surface of samples, and most of the pores and cracks are distributed parallel to the bedding, which indicated that the layered structure of coal rock samples is obvious [9].

Bedding coal rock samples and axial stress loading are shown in Figure 2. Parallel bedding coal is shown in Figure 2(a). The bedding surface is parallel to the circular ground of the sample and perpendicular to the loading direction. Vertical bedding coal is just the opposite [9]. In order to ensure the accuracy of the test, the coals in two bedding directions were shaped into $\Phi 50 \mathrm{~mm} \times \mathrm{L} 50 \mathrm{~mm}$ cylindrical standard samples according to ISRM (International Society of Rock Mechanics) standards [32]. After polishing, the difference in surface flatness of the coal rock samples is less than $0.05 \mathrm{~mm}$, and the vertical deviation of the upper and lower surfaces is less than $0.25^{\circ}$.

2.2. Test Equipment. The split Hopkinson pressure bar test system (SHPB) of Central South University was used in the experiment [33], as shown in Figure 3. The test system is composed of five parts: stress wave generator, stress wave transmission structure, confining pressure loading device, axial static pressure loading device, and super dynamic strain gauge. The coal sample is placed between the incident bar and the reflecting bar. In order to reduce friction effect at the end of sample, petrolatum is evenly smeared to both ends of coal rock sample so that the coal rock sample and the bar are in close contact. During the triaxial compression test, the hydraulic oil in oil chamber of the confining pressure device is pressurized to the target pressure, and the sample would be under a certain initial stress condition. Then, to achieve different strain rates loading, the "spinning cone" structure 


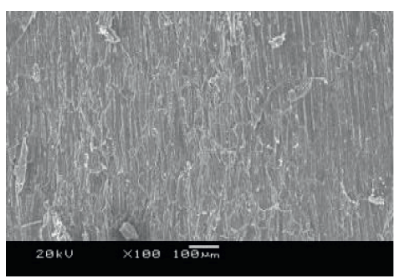

(a)

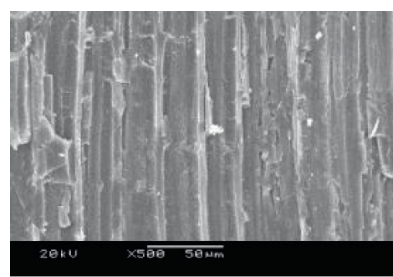

(b)

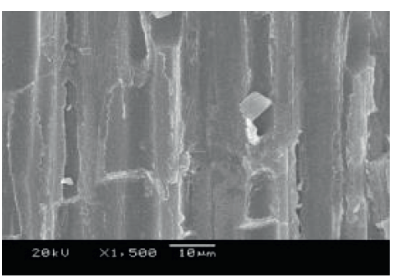

(c)

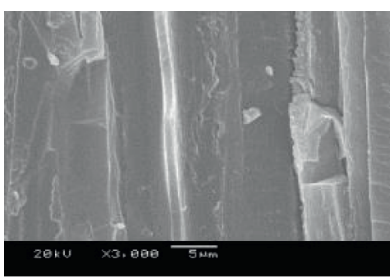

(d)

FIgURE 1: Scanning electron microscope picture of typical coal rock samples: (a) $\times 100$; (b) $\times 500$; (c) $\times 1500$; (d) $\times 3000$.

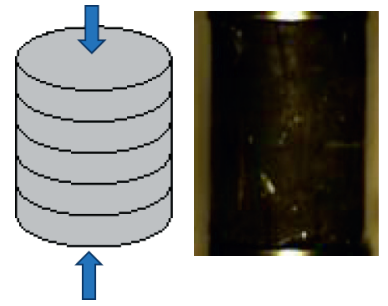

(a)

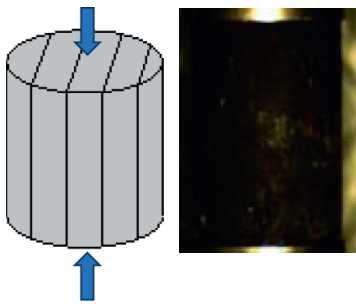

(b)

FIGURE 2: Bedding coal rock samples and loading direction: (a) parallel bedding coal; (b) vertical bedding coal.

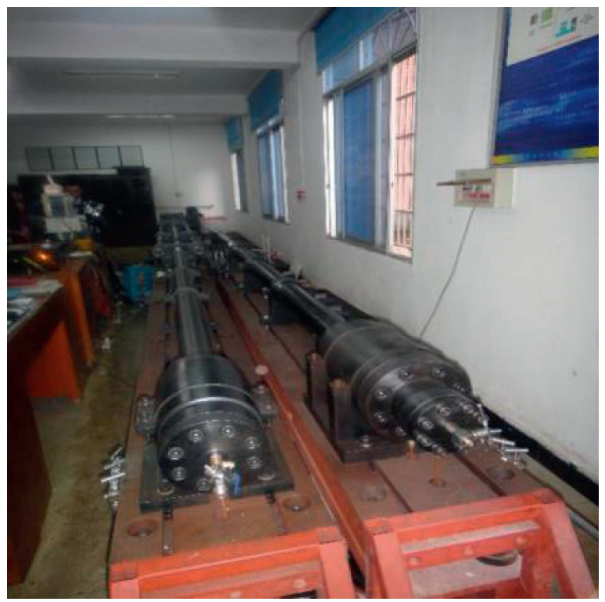

Figure 3: SHPB test device.

punch hits the incident bar at different impact speeds to generate a stable half-sine loading stress wave. After the stress wave transmits from the incident bar to coal rock sample, a part of the stress wave is absorbed by coal rock sample, a few is transmitted to the transmission bar, and the remaining part is reflected into the incident bar. The signal data are collected by strain gauge installed in the middle of the elastic bar. The elastic bars in the test system are made of $40 \mathrm{Cr}$ alloy steel. The length, diameter, density, Poisson ratio, elastic modulus, and longitudinal wave velocity of the bars are $2 \mathrm{~m}, 50 \mathrm{~mm}$, $7697 \mathrm{~kg} / \mathrm{m}^{3}, 0.28,240 \mathrm{GPa}$, and $5400 \mathrm{~m} / \mathrm{s}$, respectively.

2.3. Test Principle. Based on the assumptions of one-dimensional stress wave and uniform stress in the SHPB test, the stress, strain, and strain rate of coal rock sample could be obtained by [34]

$$
\begin{aligned}
\sigma(t) \cong \frac{E_{0} A_{0}}{A_{S}} \varepsilon_{t}(t), \\
\mathcal{\varepsilon}(t) \cong \frac{C_{0}}{L_{s}} \int_{0}^{t} \varepsilon_{r}(t) \mathrm{d} t, \\
\dot{\varepsilon}(t) \cong \frac{2 C_{0}}{L_{s}} \varepsilon_{r}(t),
\end{aligned}
$$

where $t$ is the dynamic loading time; $A_{0}, E_{0}$, and $C_{0}$ are the cross-sectional area, elastic modulus, and elastic wave velocity of elastic bar, respectively; $L_{s}$ and $A_{s}$ are the length and crosssectional area of coal rock sample; and $\varepsilon_{r}$ and $\varepsilon_{t}$ are reflected wave and transmitted wave strain signals measured in the test.

The energy carried by incident wave, reflected wave, and transmitted wave in the SHPB test can be described by [35] 


$$
\begin{aligned}
& W_{i}=\frac{A_{0}}{\rho_{0} C_{0}} \int_{0}^{t} \sigma_{i}^{2}(t) \mathrm{d} t, \\
& W_{r}=\frac{A_{0}}{\rho_{0} C_{0}} \int_{0}^{t} \sigma_{r}^{2}(t) \mathrm{d} t, \\
& W_{t}=\frac{A_{0}}{\rho_{0} C_{0}} \int_{0}^{t} \sigma_{t}^{2}(t) \mathrm{d} t,
\end{aligned}
$$

where $\rho_{0}$ is the density of elastic bar; $W_{i}, W_{r}$, and $W_{t}$ are incident energy, reflected energy, and transmitted energy, respectively; and $\sigma_{i}, \sigma_{r}$, and $\sigma_{t}$ are incident, reflected, and transmitted stress, respectively.

It is considered that most of the absorbed energy is dissipated by the crack propagation in coal rock during failure process, but a small proportion of the energy was dissipated by sound, light, and heat. Ignoring the small part of energy, the energy absorbed by coal rock samples is the dissipated energy of the crack propagation [35]:

$$
W_{d}=W_{i}-\left(W_{r}+W_{t}\right),
$$

where $W_{d}$ is the dissipated energy of coal rock in dynamic impact process.

2.4. Test Plan. In this paper, dynamic impact compression tests under four confining pressures $(0,4,8$, and $12 \mathrm{MPa})$ were carried out. On the premise of the range of the SHPB test device and the dynamic failure form of the rock, the range of strain rate was determined. The dynamic stress-strain curve was obtained by formulas (1) (3). Then, the dynamic mechanical parameters, such as average strain rate, dynamic compressive strength, and dynamic peak strain, could be derived. The energy variables in the process of dynamic rock failure, including incident energy, reflected energy, transmitted energy, and dissipated energy, can be obtained by formulas $(4) \sim(7)$.

\section{Results and Discussion}

3.1. Dynamic Stress Equilibrium. The axial inertia effect of the specimen cannot be ignored in dynamic impact compression experiment $[36,37]$. Based on the assumption of one-dimensional stress wave, the stress balance on both sides of all specimens is verified. Figure 4(a) shows the typical stress equilibrium state from a vertical bedding coal rock with a strain rate of $78.14 \mathrm{~s}^{-1}$ under the uniaxial compression test. Figure 4(b) shows the typical stress equilibrium state from a vertical bedding coal rock with a strain rate of $168.20 \mathrm{~s}^{-1}$ under the triaxial compression test. There is an acceptable difference between transmission stress and the sum of incident stress and reflected stress during the loading process, which indicates that the samples have achieved dynamic stress balance. Thus, the stress at both ends of specimen is basically the same in the impact compression experiment.

\subsection{Dynamic Mechanical Characteristics of Bedding Coal.} The dynamic stress-strain curves of vertical bedding coals under different strain rates and four confining pressures are shown in Figure 5, and the dynamic stress-strain curves of parallel bedding coals are shown in Figure 6. After a brief and inconspicuous compaction stage, the stress increases approximately linearly in the linear elastic stage. Then, it goes through the nonlinear growth in the plastic yield stage and finally reaches the peak value. Peak stress is considered as the compressive strength of rock under impact compression, and its corresponding strain is peak strain. After the peak, the bearing capacity of rock does not drop to 0 immediately. Meanwhile, fractured rock still has a certain bearing capacity, the postpeak stress decreases slowly with increase in strain, and this stage is regarded as the postpeak stress-softening stage. Under the same confining pressure, the deformation and dynamic compressive strength of coal rock increase significantly as strain rate increases. The ratio of the strain in the yield stage to peak strain increases, and the postpeak stress-softening effect is enhanced. Under the same strain rate, the increase in confining pressure also has an enhanced effect on the strength. With the increase in confining pressure, plastic deformation plays a dominant role in the failure process of coal rock, and it gradually transforms from brittleness to ductility $[38,39]$.

It is of great significance to analyse the compressive strength and peak strain of coal rock under dynamic failure for underground engineering safety. The dynamic compressive strength and peak strain of bedding coal rocks are shown as Figure 7. As can be seen from the figure, compressive strength and peak strain increase with increase in strain rate under the same confining pressure. As confining pressure increases, the strain rate sensitivity of compressive strength weakens, while that of peak strain is hardly affected. A similar conclusion on sandstone is also gained in Gong's research [20].

However, there are some differences between different bedding coals. Under uniaxial dynamic impact compression, the bedding structure has a weak influence on dynamic compressive strength and peak strain, which has been confirmed $[9,40]$. While in the triaxial state, the compressive strength of parallel bedding coal is greater than that of vertical bedding coal under approximate strain rate and confining pressure. The peak strain of parallel bedding coal is smaller than that of vertical bedding coal at $4 \mathrm{MPa}$ confining pressure, but the peak strain of parallel bedding coal is greater than that of vertical bedding coal at $8 \mathrm{MPa}$ confining pressure. When the confining pressure reaches $12 \mathrm{MPa}$, the difference in different bedding coals is not obvious.

Based on the change law of peak strain, some enlightenment in engineering application is obtained. When the bedding surrounding rock cavern is disturbed by the load in a fixed direction, the engineering condition is judged according to the surrounding rock stress measured at the engineering site. If the load direction is parallel to the bedding surface of rock mass and the confining pressure is lower than $8 \mathrm{MPa}$, we can increase the confining pressure to $8 \mathrm{MPa}$ through the lining and bolt support and other engineering measures. If the load direction is perpendicular to the bedding surface of rock mass and the confining pressure is higher than $4 \mathrm{MPa}$, we can reduce the confining pressure to $4 \mathrm{MPa}$ by drilling and other methods. Thereby, to enhance 


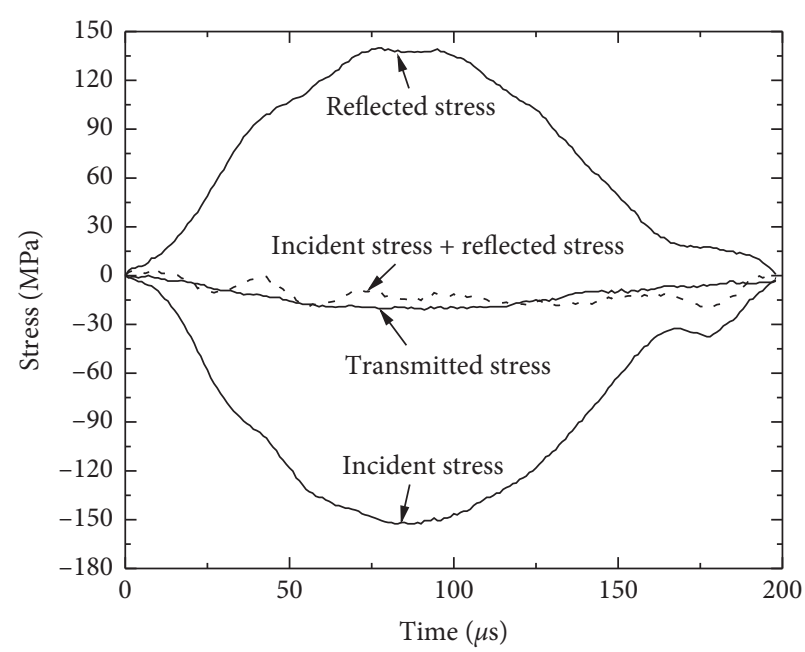

(a)

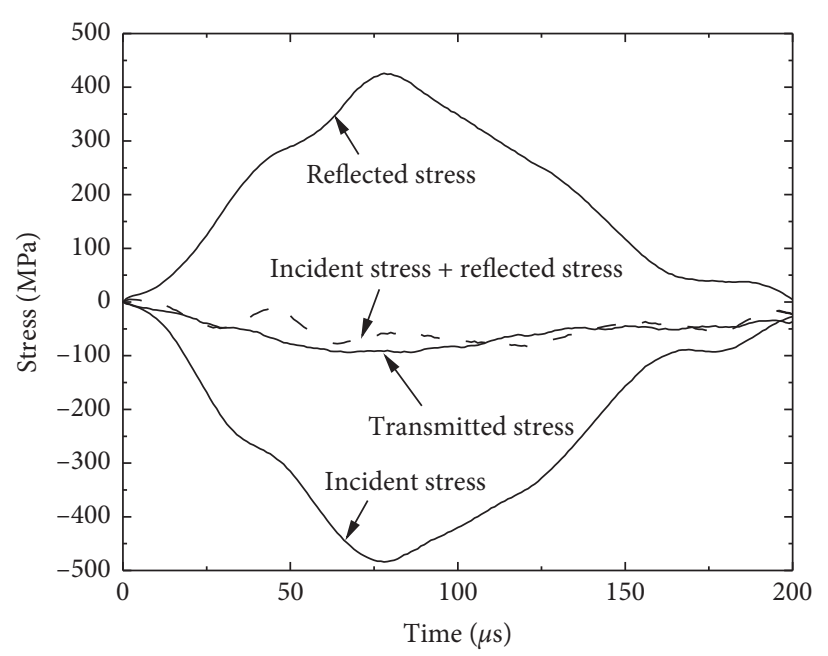

(b)

FigURE 4: Stress balance analysis: (a) uniaxial compression test; (b) triaxial compression test.

the stability of surrounding rock caverns, the distribution of surrounding rock stress can be changed by taking up engineering measures.

3.3. Energy Release Characteristics of Bedding Coal. The incident energy and dissipated energy in the process of bedding coal failure are shown in Figure 8. It can be seen from the figure that when confining pressure is constant, as strain rate increases, the incident energy and dissipation energy of bedding coal gradually increase. However, as confining pressure increases, strain rate sensitivity of energy in bedding coal rock decreases. The difference in bedding structure leads to differences in energy characteristics of coal rock. Under uniaxial compression, the bedding has a weak influence on incident energy and dissipated energy of coals. At $4 \mathrm{MPa}$ confining pressure, incident energy and dissipation energy of parallel bedding coals are greater than those of vertical bedding coals. The greater the energy dissipation, the greater damage degree in coal rock [41, 42]. If the external force is loaded along the direction of bedding structure plane at $4 \mathrm{MPa}$ confining pressure, the damage of coal rock will be greater. The rock breaking efficiency will be improved, and the excavation cycle will be reduced during excavation of layered rocks. The influence of different bedding on coal rock energy is completely opposite under $8 \mathrm{MPa}$ confining pressure, and the application of this law in rock excavation process is similar to that under $4 \mathrm{MPa}$ confining pressure. When confining pressure reaches $12 \mathrm{MPa}$, energy characteristics of coal rock tend to be hydrostatic pressure.

\subsection{Dynamic Strength Increasing Factor of Bedding Coal.} DIF represents the dynamic strength increasing factor, which is the ratio of dynamic compressive strength to static compressive strength under same confining pressure, as an indicator reflecting the magnitude of strength increases. The compressive strengths of coal rock under $0,4,8$, and $12 \mathrm{MPa}$ confining pressures are, respectively, 7.72, 26.93, 35.47, and $56.79 \mathrm{MPa}$, which can be obtained in reference [39].

The DIF of bedding coal under different confining pressures and strain rates is shown in Figure 9. Existing studies have shown that the strength, cohesion, and internal friction angle of rock have a good linear relationship with the logarithm of strain rate $[20,43]$, which also can be obtained in Figure 9. Because the plastic deformation dominates, growth rate of DIF decreases with increase in confining pressure. As confining pressure increases, coal rock changes from brittleness to ductility and plastic deformation dominates in the process of rock failure. The decrease in growth rate of DIF growth is caused by the increase in confining pressure because dynamic strength gradually stabilizes under high confining pressure [39].

Comparing the DIF growth rate of two bedding coals under different confining pressures, it is found that the DIF growth rate will be affected by the bedding. Under uniaxial impact, strain rate of coal rock with $70 \mathrm{~s}^{-1}$ as the boundary can be divided into low strain rate and high strain rate [44]. At low strain rates, the bedding planes of parallel bedding coals are prone to delamination during the crack propagation stage, leading to the weakening of bearing capacity. The stress increase with strain is small so that compressive strength is lower. Because coal framework is supported by the coal matrix, stress increases with strain and the compressive strength increase is greater. However, at high strain rates, the impact of layered structure on compressive strength weakens with increase in strain rate. Under uniaxial impact, the growth slope of DIF in parallel bedding coals is greater than that of vertical bedding coals because of the difference between low and high strain rates. Under triaxial impact load, the growth rate of DIF in vertical bedding coal is greater than that in parallel bedding coal.

3.5. Energy Distribution of Bedding Coal. The rock breaking efficiency and excavation efficiency are closely related to the economic investment of project. Making the best use of 


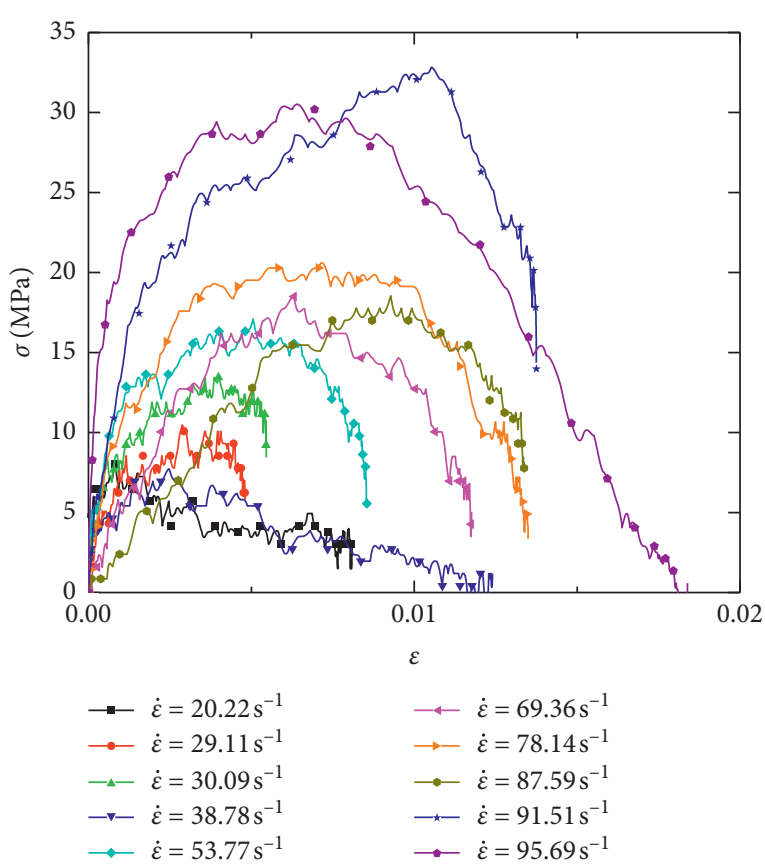

(a)

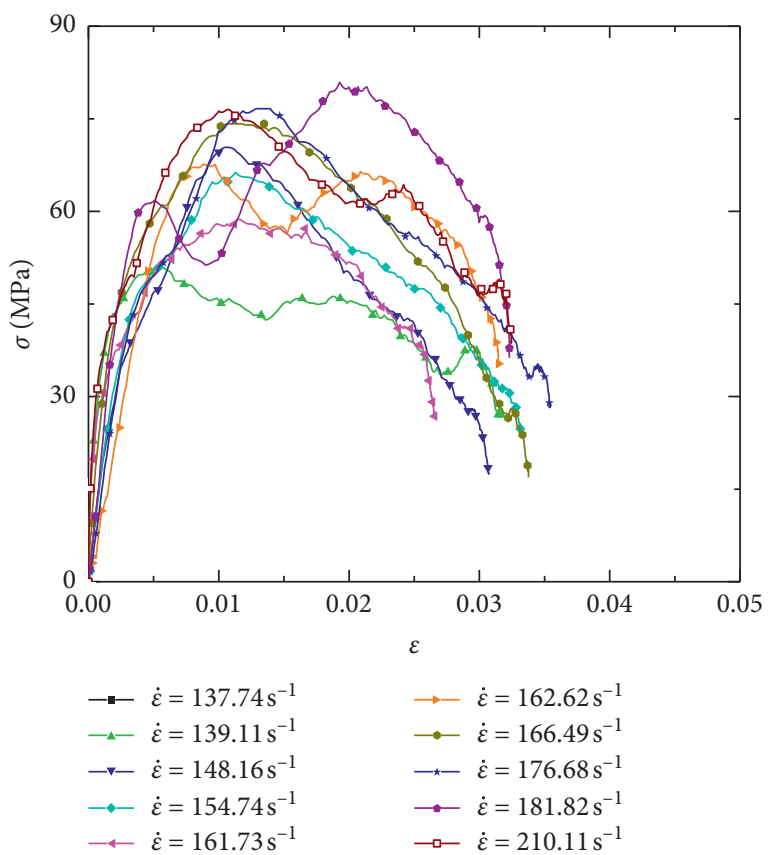

(c)

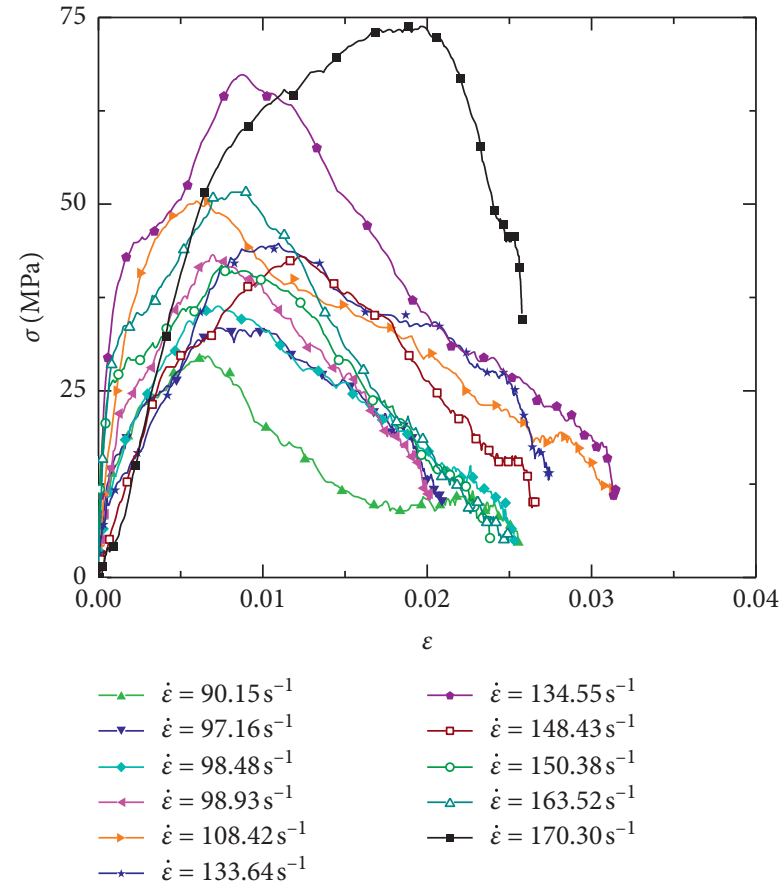

(b)

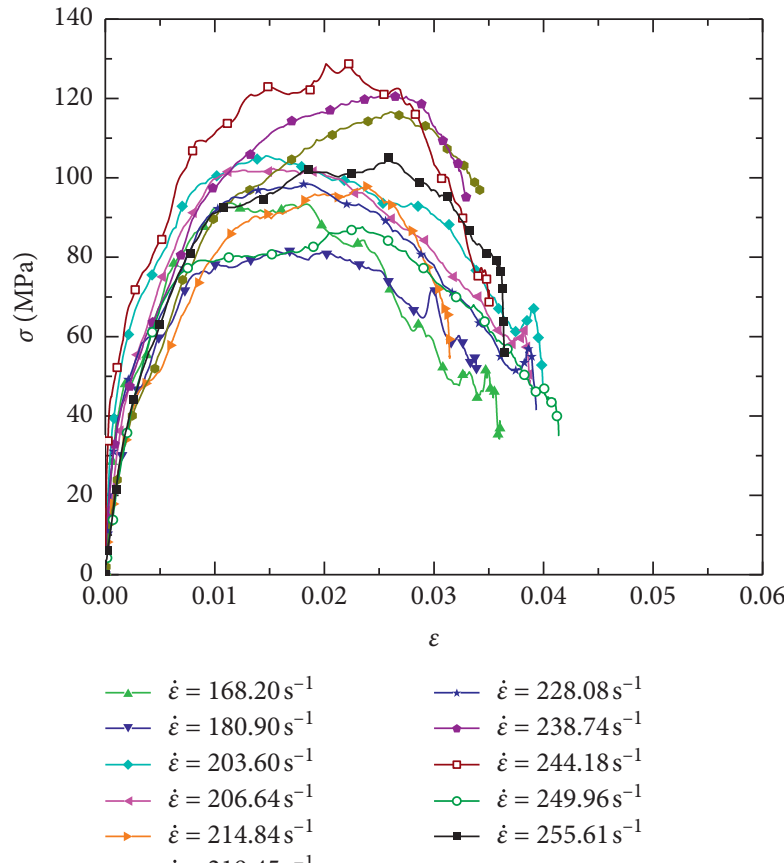

(d)

FIgURE 5: Dynamic stress-strain curve of vertical bedding coal: (a) $\sigma_{3}=0 \mathrm{MPa}$; (b) $\sigma_{3}=4 \mathrm{MPa}$; (c) $\sigma_{3}=8 \mathrm{MPa}$; (d) $\sigma_{3}=12 \mathrm{MPa}$.

resources to achieve efficient rock breaking and efficient excavation deserves our attention. Actually, rock failure is a process of external input energy converting into rock dissipation energy. The degree of rock failure is directly reflected through energy conversion efficiency. In the SHPB test, energy dissipation ratio $\eta$ is the ratio of dissipated energy to incident energy, which reflects the energy distribution ratio during rock failure. The dissipation ratio $\eta$ of bedding coals under different strain rates is shown in Figure 10 . When confining pressure is constant, $\eta$ is within a certain range as the strain rate increases and the range varies with confining pressures.

In order to better distinguish the range of dissipation ratios under different confining pressures, the dissipation ratios that are under the same confining pressure are concentrated in a box plot, as shown in Figure 11. It can be seen from Figure 11 that 


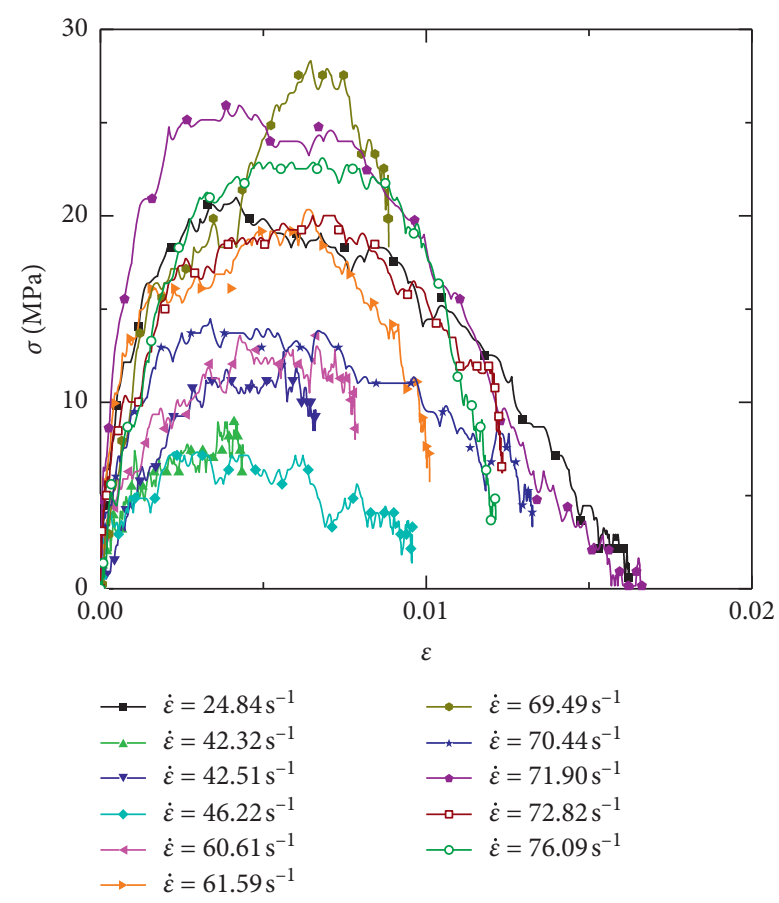

(a)

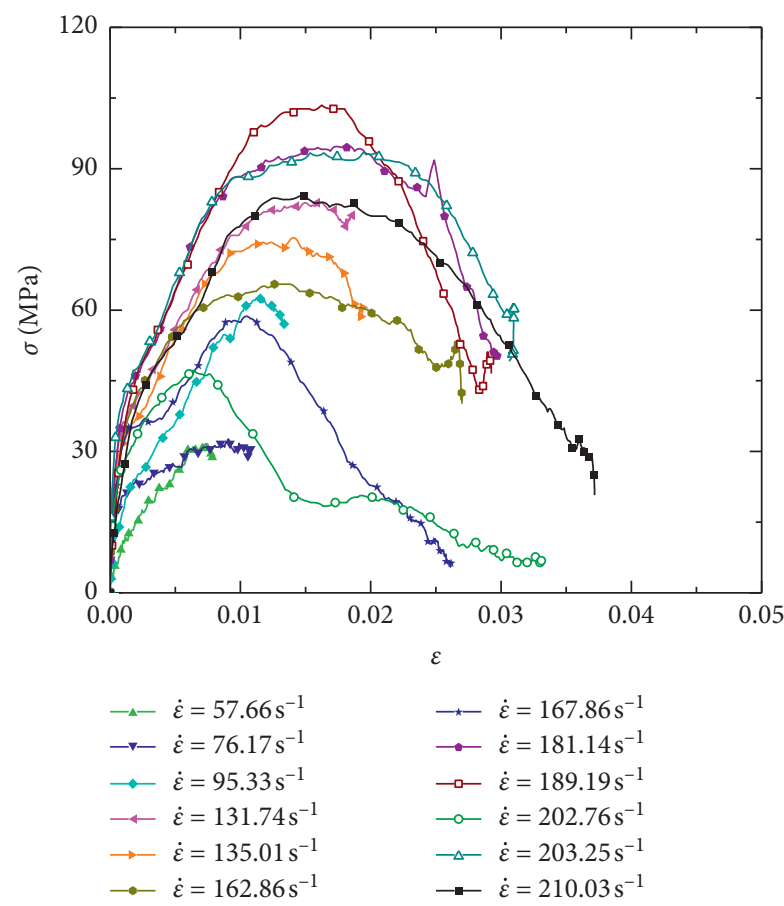

(c)

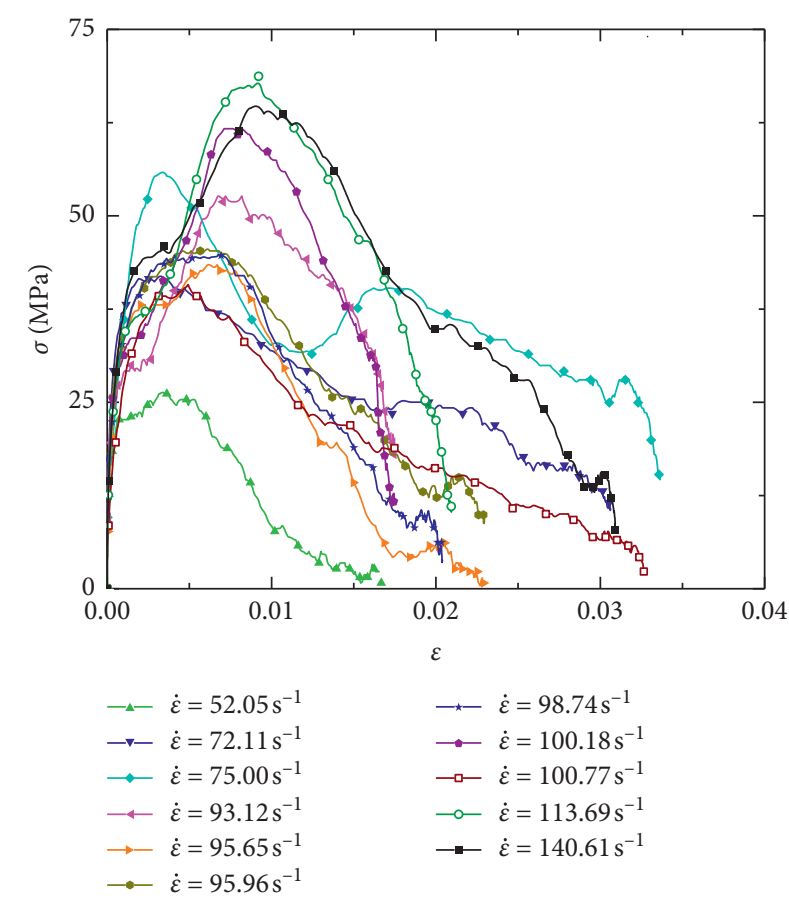

(b)

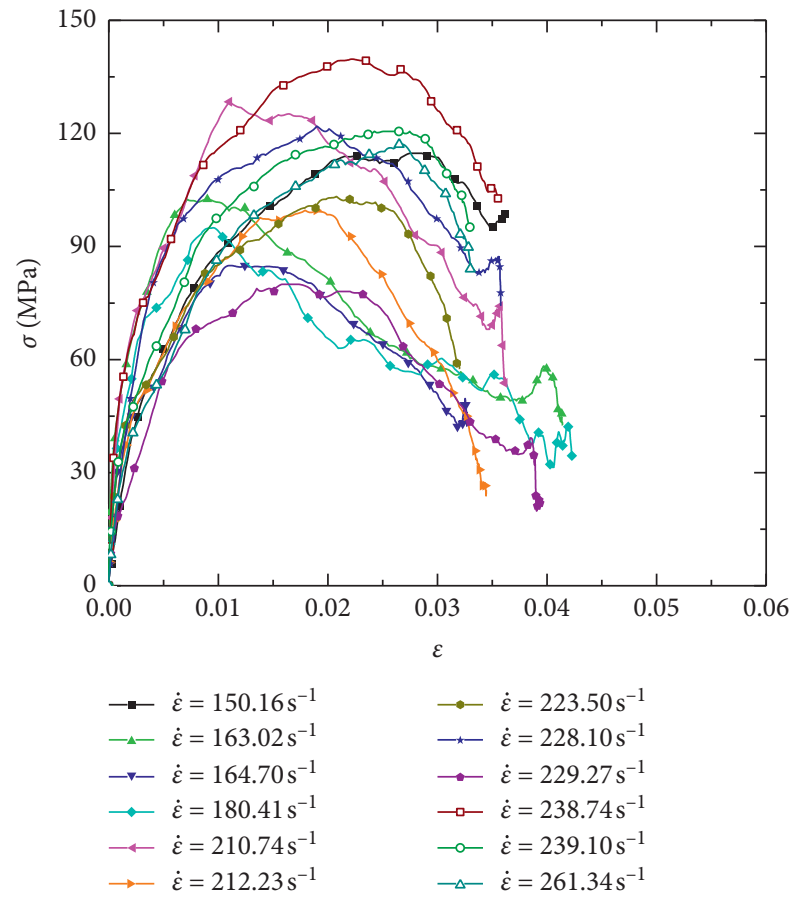

(d)

FIgure 6: Dynamic stress-strain curve of parallel bedding coal: (a) $\sigma_{3}=0 \mathrm{MPa}$; (b) $\sigma_{3}=4 \mathrm{MPa}$; (c) $\sigma_{3}=8 \mathrm{MPa}$; (d) $\sigma_{3}=12 \mathrm{MPa}$.

when confining pressure is constant, the dissipation ratio of coal rock at different strain rates is approximately normally distributed along the mean. The influence of confining pressure on energy distribution can be better quantitatively analysed through the average dissipation ratio. It can be clearly seen that the energy dissipation ratio of rock failure in the triaxial state is greater than that of the uniaxial state. Under uniaxial impact compression, the dissipation ratio of vertical bedding coal is 


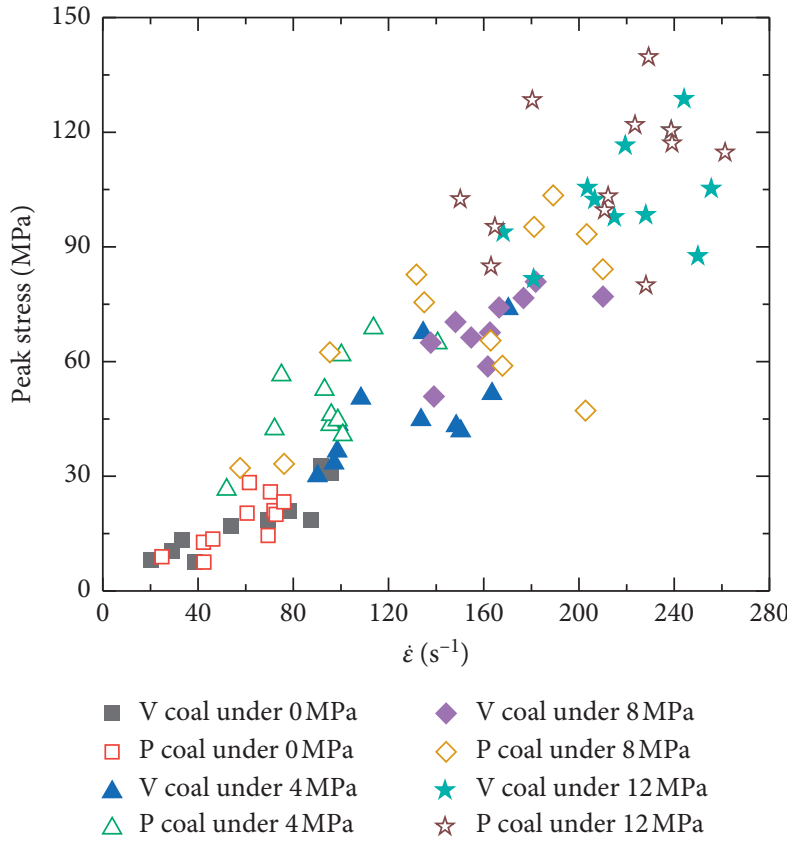

(a)

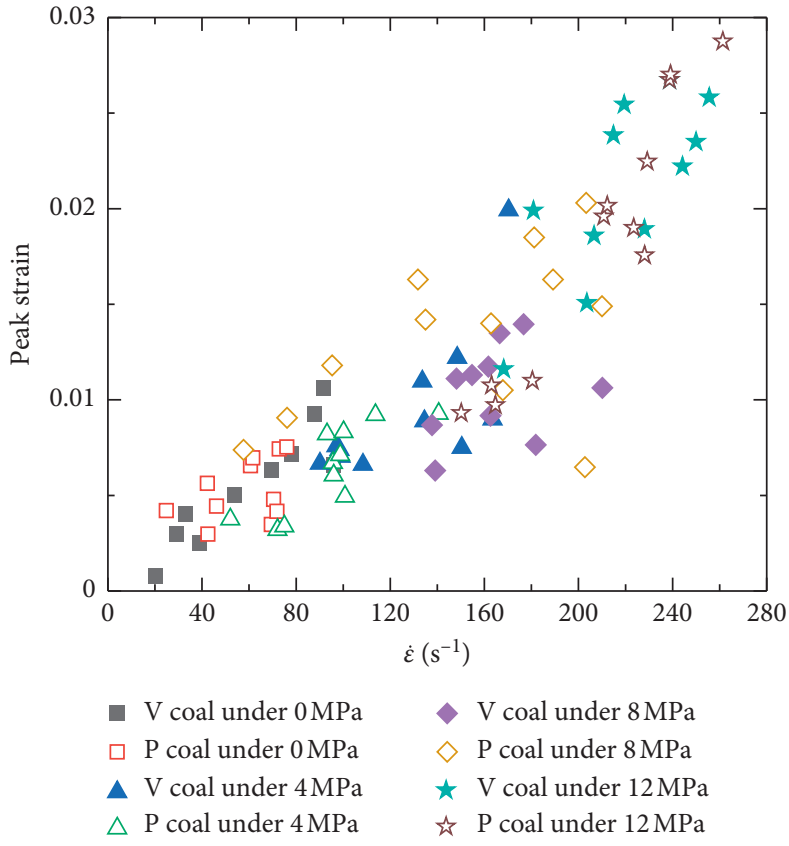

(b)

FIGURE 7: Dynamic compressive strength and peak strain of bedding coal: V stands for vertical bedding and P stands for parallel bedding: (a) peak stress; (b) peak strain.

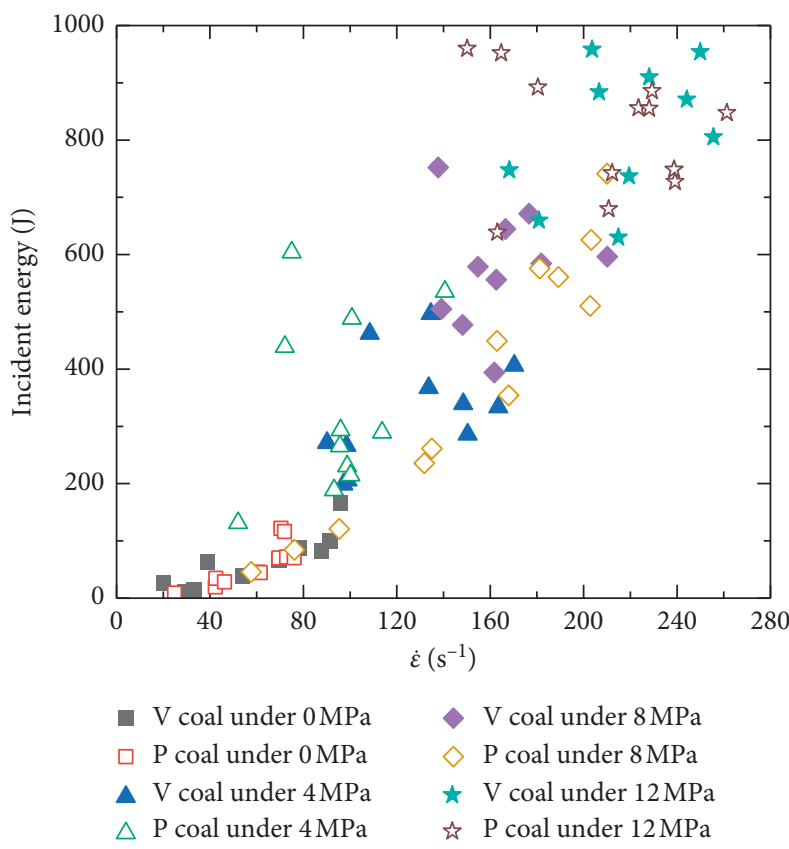

(a)

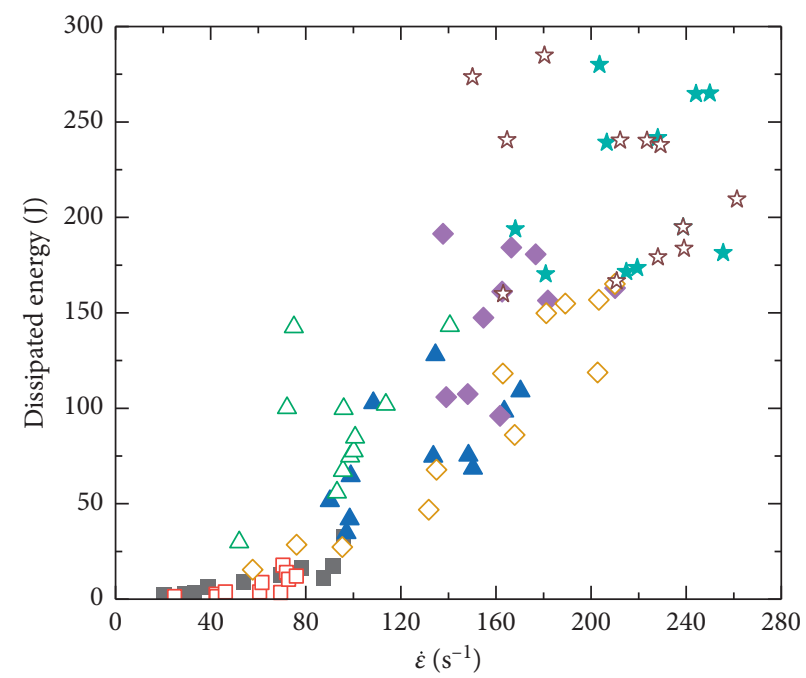
- V coal under $0 \mathrm{MPa}$
V coal under $8 \mathrm{MPa}$
$\square \mathrm{P}$ coal under $0 \mathrm{MPa}$
$\diamond \mathrm{P}$ coal under $8 \mathrm{MPa}$
- $\mathrm{V}$ coal under $4 \mathrm{MPa}$
$\star \mathrm{V}$ coal under $12 \mathrm{MPa}$
$\triangle \mathrm{P}$ coal under $4 \mathrm{MPa}$

(b)

FIGURE 8: (a) Incident energy and (b) dissipated energy of bedding coal.

larger than that of parallel bedding, and the energy conversion rate of external load imposed along the direction of bedding structure is higher. The energy distribution law of two bedding coals at $4 \mathrm{MPa}$ is opposite to that at $0 \mathrm{MPa}$. The influence of layered structure on energy distribution weakens with the increase in confining pressure. 


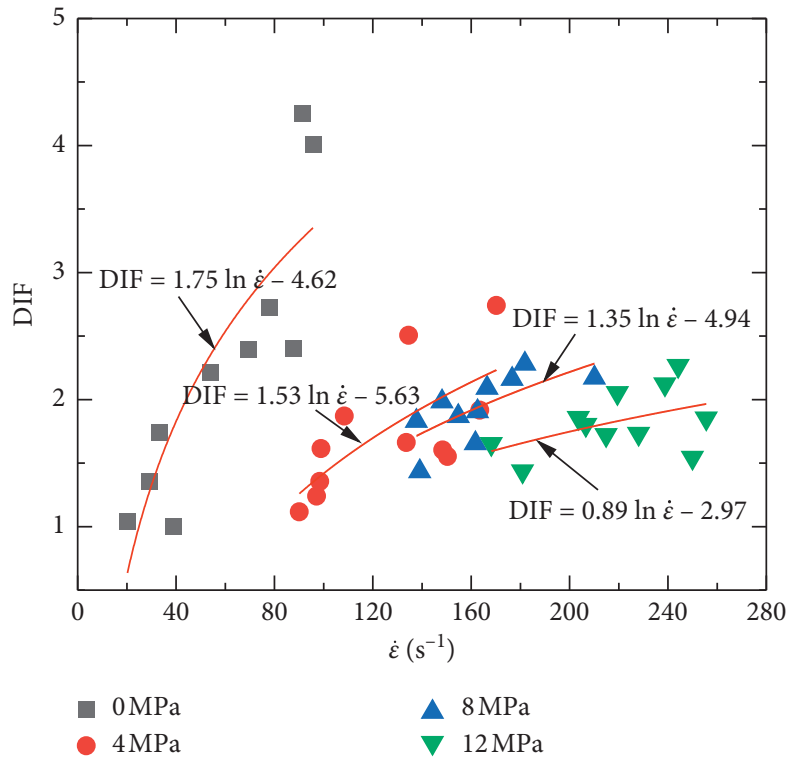

(a)

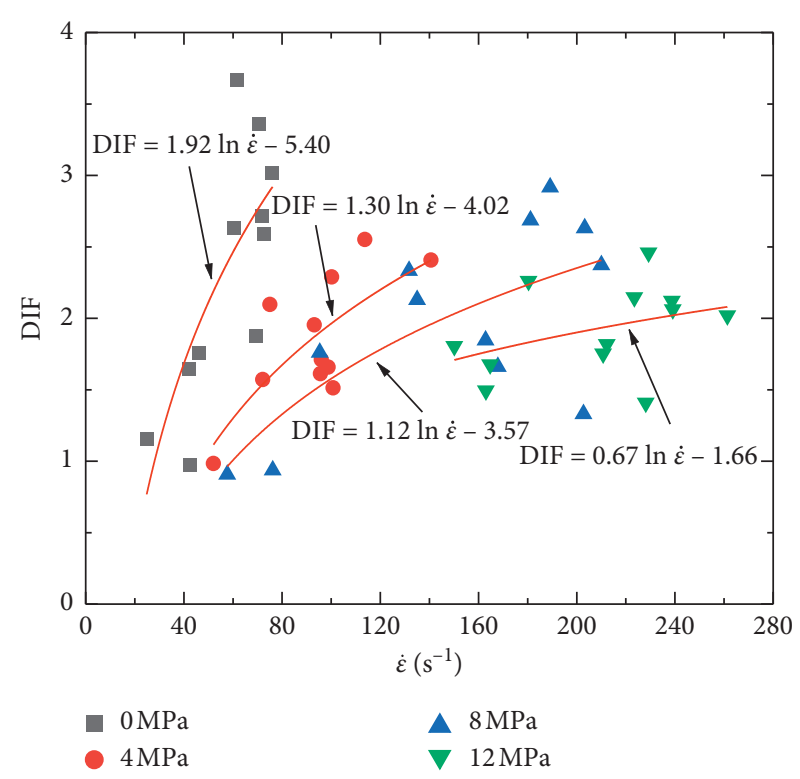

(b)

FIGURE 9: Dynamic strength increasing factor of bedding coals: (a) vertical bedding coal; (b) parallel bedding coal.

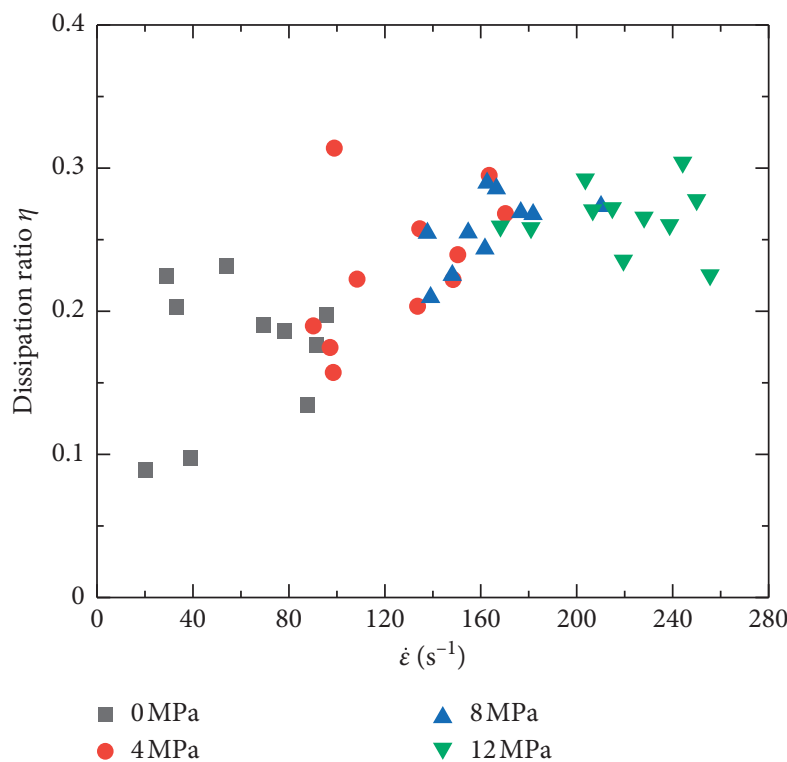

(a)

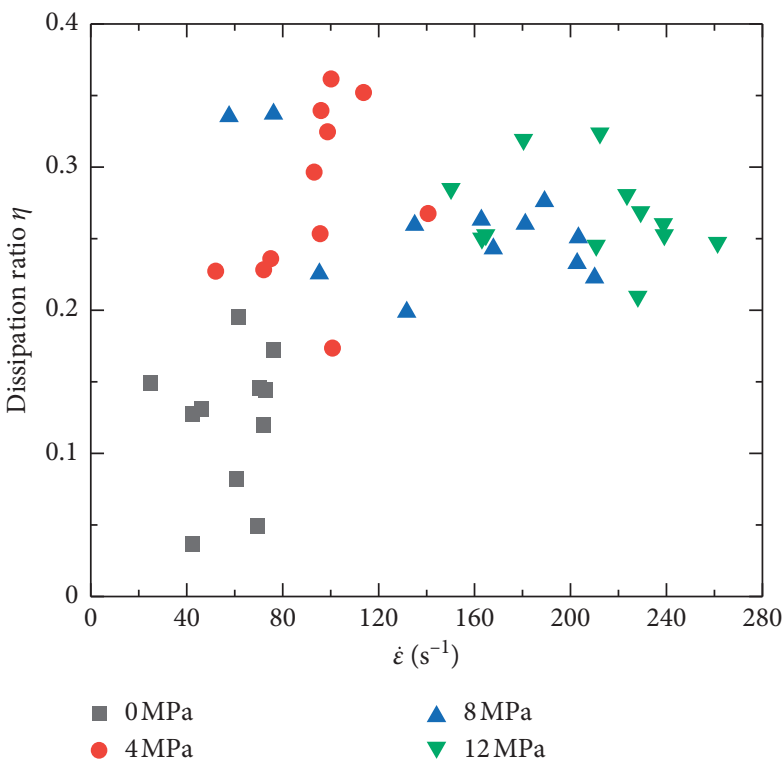

(b)

FIGURE 10: Dissipation ratio of coal rock at different strain rates: (a) vertical bedding coal; (b) parallel bedding coal.

\section{Dynamic Constitutive Model}

It can be seen from the above analysis that the confining pressure and strain rate are important factors affecting the dynamic impact compression characteristics. At the same time, under certain confining stress conditions and strain rate loading conditions, the effect of bedding structure on dynamic failure cannot be ignored. Rock damage is caused by energy dissipation, and the dynamic constitutive equation of rock established from the perspective of energy is closer to the essence of rock failure. In order to reflect the combined effect of bedding, confining pressure, and strain rate on the dynamic failure characteristics of coal rock, the triaxial dynamic constitutive model of coal rock is established based on the energy balance equation of rock failure, where DIF and the comprehensive influence coefficient $K$ are introduced.

4.1. The Energy Balance Equation of Rock Failure. The process of rock damage is a process of energy dissipation. According to the theory of irreversible thermodynamics, the work done 


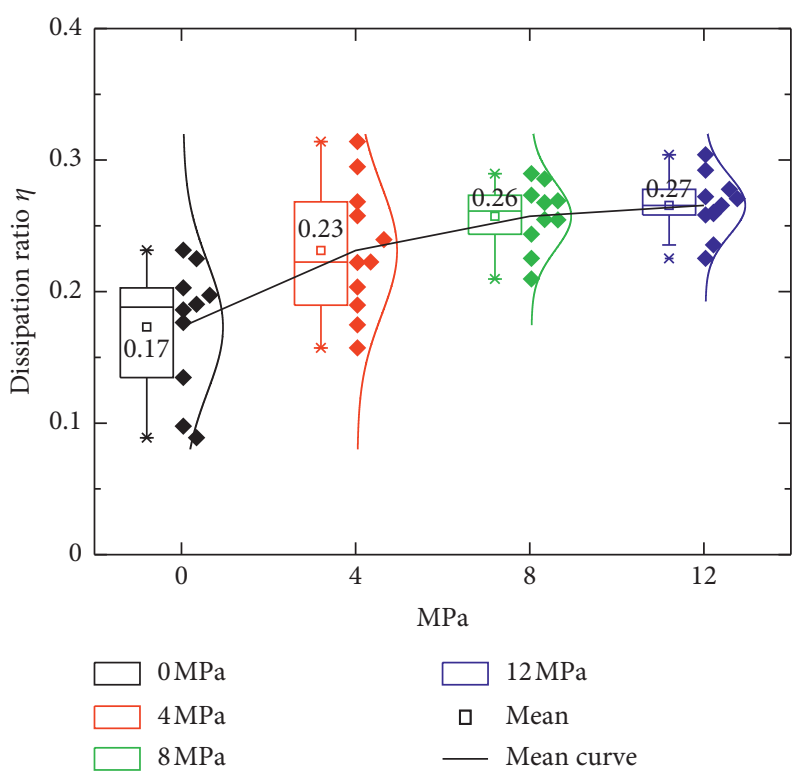

(a)

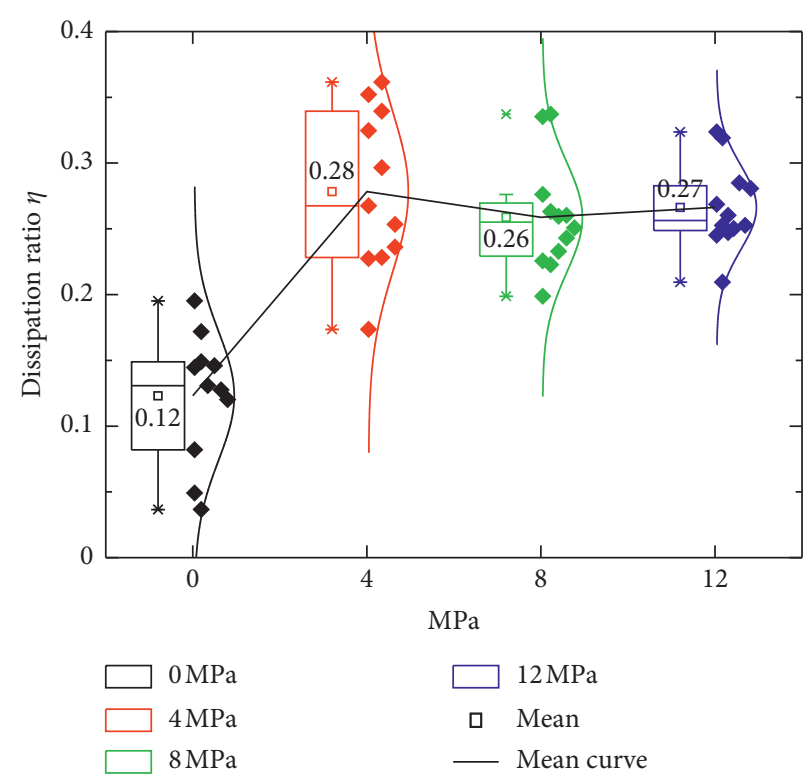

(b)

Figure 11: Dissipation ratio of coal rock under different confining pressures: (a) vertical bedding coal; (b) parallel bedding coal.

by external forces is transformed into structural strain energy, damaging dissipation energy stored in the rock mass. In the process of rock deformation and failure, the structural strain energy gradually transforms into damage dissipation energy. The damage of the structural phase is the damage phase, which leads to irreversible damage and deformation of the rock mass [45-47]. A rock mass unit with a volume of $V$ is represented by the structural phase volume $V_{n}$ and the damage phase volume $V_{d}$. The rock mass unit will deform and fail after being compressed, sheared, and stretched. The input energy of external force is transformed into elastic strain energy and damage dissipation energy. Assuming that there is no heat exchange with the external system during the destruction of rock, it can be obtained from the first law of thermodynamics that

$$
W=W_{E}+\Omega V_{d}
$$

where $W$ is the total energy input by external force; $W_{E}$ is the elastic strain energy stored in the structural phase; and $\Omega$ is the dissipation energy per unit damage volume.

As the stress $\sigma_{n}$ increases, the volume of the structural phase continues to decrease, while the volume of the damage phase increases. The undamaged structural phase rock mass is linear elastic, and its elastic strain energy is calculated according to the linear elastic body. The structure phase volume is $V_{n}$. When the increment of the damage phase volume is $d V_{d}$, the strain increment produced by the structural phase is $d \varepsilon_{n}$. The damage dissipation energy can be expressed as

$$
d \Omega=V_{n} \frac{1}{2} \sigma_{n} d \varepsilon_{n}
$$

In addition, according to the theory of irreversible thermodynamics, the failure of rock mass is a process of the microcracks in the rock mass initiating, expanding, developing, and penetrating. The essence of increasing damage is the result of energy dissipation. When the volume increment of the damage phase is $d V_{d}$, the energy dissipated by the rock mass element is

$$
d \Omega=\frac{\mathrm{d} \Omega}{\mathrm{d} V_{d}} d V_{d}=\Omega d V_{d}
$$

The dissipated energy required to transform the structural phase into the damaged phase is equal to the increase in energy dissipated in the process of rock failure. We establish an energy balance equation for dissipated energy based on this relationship:

$$
\Omega d V_{d}=V_{n} \frac{1}{2} \sigma_{n} d \varepsilon_{n} .
$$

4.2. Damage Equation. According to the definition of the classical continuum damage variable,

$$
D=\frac{V_{d}}{V}=\frac{V_{d}}{V_{n}+V_{d}} .
$$

From equation (12), the damage variable expression is

$$
\frac{1}{2}(1-D) \sigma_{n} d \varepsilon_{n}=\Omega d D .
$$

Sorting out equation (13), we get 


$$
d D=\frac{1}{2 \Omega}(1-D) \sigma_{n} d \varepsilon_{n}
$$

It can be seen from the above damage variable equation that the smaller the dissipation energy per unit damage volume of diffusion $\Omega$ is, the greater the stress $\sigma_{n}$ becomes, and the damage is easier to develop. These characteristics are consistent with the general law of rock damage.

Integrating equation (14), we get

$$
D=1-\exp \left(-\frac{1}{2 \Omega} \int \sigma_{n} \mathrm{~d} \varepsilon_{n}\right)
$$

The stress $\sigma_{n}$ in the damage equation (15) is calculated according to the SIR model [48].

$$
\sigma_{n}=c\left(e^{\left(b \varepsilon / \varepsilon_{\max }\right)}-e^{\left(a \varepsilon / \varepsilon_{\max }\right)}\right) \sigma_{c},
$$

where $a, b$, and $c$ are constants related to the rock material and $\sigma_{c}$ is the dynamic compressive strength of the rock.

Substituting equation (16) into equation (15),

$$
D=1-\exp \left(-\frac{1}{2 \Omega} \int c\left(e^{\left(b \varepsilon / \varepsilon_{\max }\right)}-e^{\left(a \varepsilon / \varepsilon_{\max }\right)}\right) \sigma_{c} \mathrm{~d} \varepsilon_{n}\right) \text {. }
$$

4.3. Constitutive Model considering Confining Pressure, Bedding, and Strain Rate. It can be seen from the analysis in Section 2.4 that the growth of dynamic strength is affected by bedding, confining pressure, and strain rate. Introducing DIF into the constitutive model can better reflect the influence of the three factors on the dynamic failure characteristics of rock [49]. According to the definition of DIF, the following can be obtained:

$$
\sigma_{c}=\mathrm{DIF} \times \sigma_{0}
$$

From the analysis in Section 2.5, it can be seen that bedding, confining pressure, and strain rate have complex effects on energy dissipation. Therefore, a comprehensive influence coefficient $K$ is also introduced before $\Omega$ of formula (17) to describe the degree in the influence of bedding, confining pressure, and strain rate on the energy distribution of coal rock. $K$ is between 0 and 1 . The larger the $K$ value is, the smaller the impact on energy distribution is. Because the damage volume is not easy to calculate, $\Omega$ can be changed into

$$
\Omega=K \frac{W_{d}}{V_{d}}=K \frac{V}{V_{d}} \times \frac{W_{d}}{V}
$$

According to continuum damage mechanics, the damage variable can be defined as

$$
D^{\prime}=\frac{V_{d}}{V}
$$

In this paper, the energy damage variable of dynamic failure of coal rock is used to express the damage degree of rock mass structural phases $D^{\prime}[50]$.

$$
\Omega=\frac{K}{D^{\prime}} \times U_{d}
$$

where $U_{d}$ is the ratio of the dissipated energy to the volume of coal rock sample, called the energy consumption density.

According to the principle of equivalent strain,

$$
\sigma=E \varepsilon(1-D) \text {. }
$$

Under dynamic impact compression, as the confining pressure increases, the plastic deformation of coal becomes more and more obvious. Therefore, this paper introduces the correction coefficient $e$ to describe the nonlinear characteristics of the plastic yield stage:

$$
\sigma=E \varepsilon^{e}(1-D)
$$

According to formulas (17), (18), (21), and (23), we can obtain the dynamic constitutive equation of coal rock:

$$
\sigma=E \varepsilon^{e}(1-D)=E \varepsilon^{e} \exp \left(-\frac{D^{\prime}}{2 K U_{d}} \int c\left(e^{\left(b \varepsilon / \varepsilon_{\max }\right)}-e^{\left(a \varepsilon / \varepsilon_{\max }\right)}\right) \mathrm{DIF} \sigma_{0} \mathrm{~d} \varepsilon_{n}\right) .
$$

In the formula, $D^{\prime}, E, \varepsilon_{\max }$, DIF, and $\sigma_{0}$ can be obtained by indoor uniaxial and triaxial SHPB impact compression tests; the parameters $a, b, c, K$, and $e$ can be obtained by fitting the test data.

4.4. Model Validation. After a lot of fitting attempts, some parameters have been obtained. It is found that the parameter $a$ is generally less than 0 . The smaller the value of $a$ is, the better fitting effect is. When the value of parameter $a$ is -30 , the dynamic failure stress-strain curve of bedding coal can be fitted well. The parameter $c$ is greater than 0 , and the value of $c$ is generally between 1 and 6 . When the value of $c$ is $3, c$ can be applied to the dynamic stress-strain curve of most coals. The parameter $b$ plays an important role in controlling the constitutive model curve. Under uniaxial compression, the value of $b$ is greater than 0 , but under triaxial compression, the value of $b$ is less than 0 . The parameter $e$ is usually around 1 . The larger the value of $e$ is, the greater the proportion of the deformation in the plastic yield stage to the prepeak strain is. These model parameters are almost 
TABLE 1: Basic parameters of coal rock dynamic constitutive model.

\begin{tabular}{lccccccccc}
\hline Sample & $\sigma_{3}(\mathrm{MPa})$ & Bedding & $\dot{\varepsilon}\left(\mathrm{s}^{-1}\right)$ & DIF & $U_{d}\left(\mathrm{~J} \cdot \mathrm{cm}^{-3}\right)$ & $\sigma_{0}(\mathrm{MPa})$ & $\varepsilon_{\max }$ & $E(\mathrm{MPa})$ & $D^{\prime}$ \\
\hline $0-1$ & 0 & $\mathrm{P}$ & 70.44 & 3.36 & 0.20 & 7.72 & 0.0048 & 15643 & 0.735 \\
$0-2$ & 0 & $\mathrm{~V}$ & 69.36 & 2.40 & 0.14 & 7.72 & 0.0063 & 4004 & 0.957 \\
$4-1$ & 4 & $\mathrm{P}$ & 98.74 & 1.66 & 0.82 & 26.93 & 0.0071 & 29727 & 1.000 \\
$4-2$ & 4 & $\mathrm{~V}$ & 163.52 & 1.92 & 1.09 & 26.93 & 0.0090 & 36566 & 1.000 \\
$8-1$ & 8 & $\mathrm{P}$ & 162.86 & 1.85 & 1.32 & 35.47 & 0.0140 & 25219 & 0.874 \\
$8-2$ & 8 & $\mathrm{~V}$ & 161.73 & 1.66 & 1.01 & 35.47 & 0.0117 & 36566 & 0.778 \\
$12-1$ & 12 & $\mathrm{P}$ & 164.70 & 1.68 & 2.65 & 56.79 & 0.0097 & 20829 & 0.971 \\
$12-2$ & 12 & $\mathrm{~V}$ & 168.20 & 1.65 & 2.19 & 56.79 & 0.0116 & 26278 & 0.838 \\
$4-3$ & 4 & $\mathrm{~V}$ & 97.16 & 1.24 & 0.38 & 26.93 & 0.0076 & 16732 & 0.727 \\
$4-4$ & 4 & $\mathrm{~V}$ & 133.64 & 1.66 & 0.84 & 26.93 & 0.0110 & 11276 & 0.968 \\
\hline
\end{tabular}

$\mathrm{V}$ stands for vertical bedding, and $\mathrm{P}$ stands for parallel bedding.

TABLE 2: Material parameters of the coal rock dynamic constitutive model.

\begin{tabular}{lcccccc}
\hline Sample & $a$ & $B$ & $c$ & $e$ & $K$ & Correlation coefficient $R^{2}$ \\
\hline $0-1$ & -30 & 0.1 & 3 & 0.97 & 0.61 & 0.91 \\
$0-2$ & -30 & 0.1 & 3 & 1.11 & 0.95 & 0.89 \\
$4-1$ & -30 & -0.17 & 3 & 0.98 & 0.30 & 0.89 \\
$4-2$ & -30 & -0.01 & 3 & 1.08 & 0.40 & 0.90 \\
$8-1$ & -30 & -0.67 & 3 & 1.00 & 0.37 & 0.91 \\
$8-2$ & -30 & -0.37 & 3 & 1.09 & 0.41 & 0.82 \\
$12-1$ & -30 & -0.29 & 3 & 0.92 & 0.37 & 0.94 \\
$12-2$ & -30 & -0.07 & 3 & 1.03 & 0.58 & 0.92 \\
$4-3$ & -30 & -0.01 & 3 & 1.05 & 0.65 & 0.91 \\
$4-4$ & -30 & -0.01 & 3 & 1.01 & 0.77 & 0.92 \\
\hline
\end{tabular}

confirmed, which leads to better applicability of the model. However, the $K$ value is an important parameter that affects the dynamic characteristics in the model.

Part of the data is shown due to the large number of trials. The basic parameters in Table 1 can be obtained through conventional triaxial tests. Based on Table 1, the model material parameters in Table 2 can be obtained. Samples $0-2,4-2,8-1$, and $12-2$ are the fitting results of vertical bedding coals loaded at approximate strain rates under three confining pressures and the results under uniaxial loading, as shown in Figure 12(a). It can be seen from the figure that the $K$ value of bedding coals gradually increases with the increase in confining pressure. Figure 12(b) shows the fitting results of parallel bedding coals under four confining pressures, concluding coal samples $0-1,4-1,8-1$, and 12-1. Compared with the two bedding coals at similar strain rates under the same confining pressure, it can be seen that the $K$ value of the vertical bedding coal is greater than that of the parallel bedding coal. It shows that the vertical bedding structure has less influence on energy distribution when the confining pressure is constant. The influence of strain rate on $K$ value is similar under the same confining pressure. As an example of $4 \mathrm{MPa}$ confining pressure, samples 4-2, 4-3, and 44 are the fitting results of vertical bedding coal with different strain rates, which are shown in Figure 12(c). It can be seen that under the same confining pressure, the $K$ value of bedding coal first increases and then decreases as the strain rate increases. The $K$ value can be used to judge the energy distribution of bedding coal rock under specific confining pressure and strain rate conditions. The optimal energy utilization rate can be obtained by adjusting the angle between the loading direction and the bedding direction, which has reference significance for improving the efficiency of engineering such as rock blasting excavation, mining crushing, and surrounding rock support. In this paper, two directions of $0^{\circ}$ and $90^{\circ}$ between the load loading direction and the bedding plane direction are studied. The energy distribution in the direction of multiangle bedding still needs further research.

According to the above analysis, it is not difficult to see that the constitutive model established based on energy theory can better reflect the dynamic failure characteristics and the correlation coefficients of the fitting curves are all high. In addition, the rock burst discrimination indicators such as the falling modulus index DMI, energy storage consumption index, and impact energy index are all obtained from the full stress-strain curve [51]. However, the previous constitutive models cannot well simulate the characteristics of the rock postpeak stage and are insufficient for obtaining the full stress-strain characteristics. In this paper, it can be seen from Figure 10 that the rock triaxial dynamic constitutive model established in this paper can better reflect the characteristics of postpeak stress softening, which is of great significance for the identification and prevention of rock bursts. 


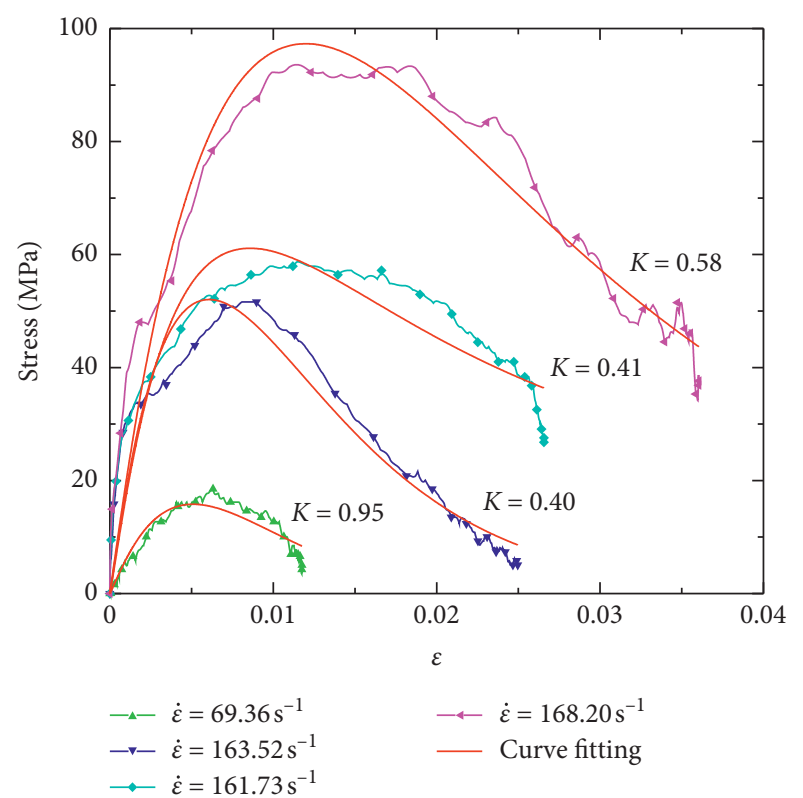

(a)

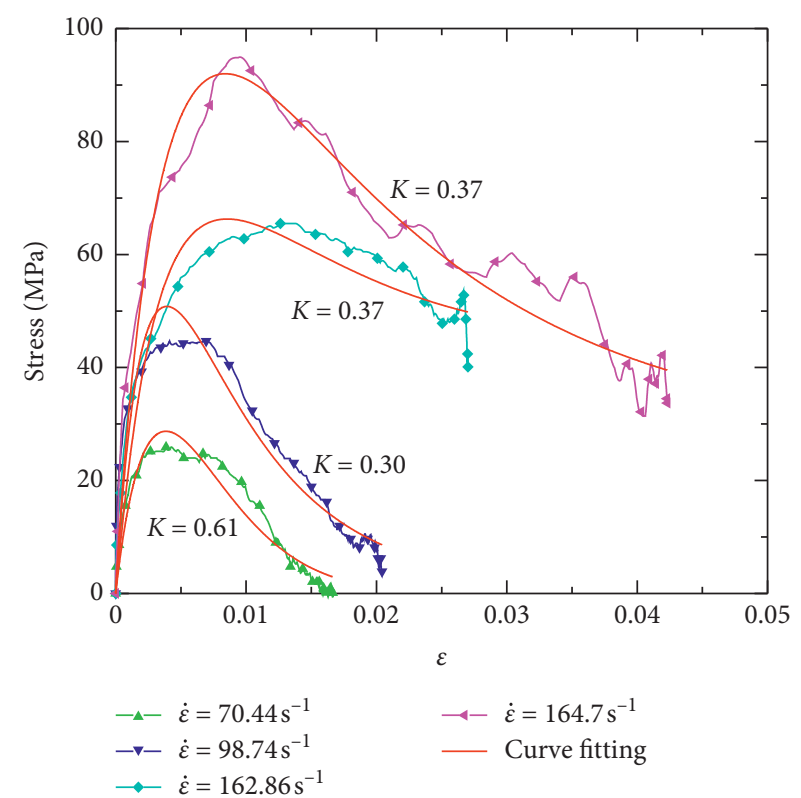

(b)

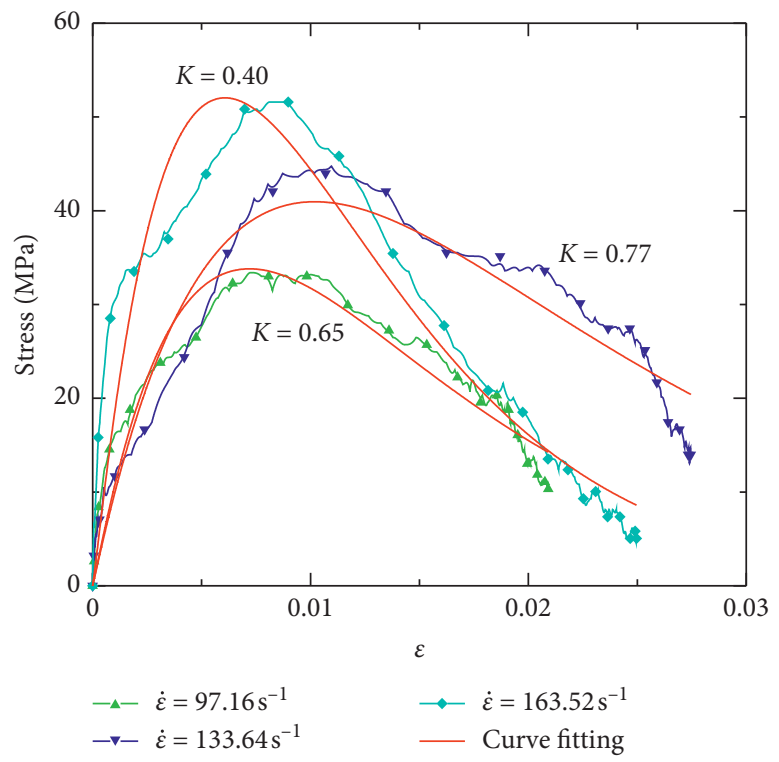

(c)

FIGURE 12: Simulation verification of coal dynamic constitutive equation: (a) vertical bedding coal; (b) parallel bedding coal; (c) $\sigma_{3}=4 \mathrm{MPa}$.

\section{Conclusion}

In this paper, impact compression tests on bedding coals under different confining pressures and different strain rates are carried out, and a dynamic constitutive model of bedding coals is established based on energy theory.

(1) Confining pressure and strain rate are important factors that affect the dynamic mechanical parameter properties of coal. When the confining pressure is constant, as strain rate increases, the compressive strength, peak strain, incident energy, and dissipation energy of bedding coals gradually increase. As confining pressure increases, the strain rate dependence of these parameters decreases except for peak strain.

(2) The bedding structure has a weaker influence on the compressive strength, peak strain, incident energy, and dissipated energy of coal under uniaxial compression. Under triaxial compression, the compressive strength of parallel bedding coal is greater than that of vertical layers coal rock. Different bedding of coal rock leads to differences in peak strain, incident energy, and dissipation energy under different confining pressures. As the confining pressure increases, the degree of difference caused by bedding decreases. Under certain stress conditions, a 
reasonable arrangement of loads and bedding directions is conducive to improve the rock breaking effect and the stability of surrounding rock caverns.

(3) DIF increases linearly with the increase in the strain rate logarithm, and the increase in confining pressure reduces the growth rate. Under the confining pressures of $0,4,8$, and $12 \mathrm{MPa}$, the DIF growth rates of vertical bedding coals are $1.75,1.53,1.35$, and 0.89 , respectively, and the DIF growth rates of parallel bedding coals are $1.92,1.30,1.12$, and 0.67 , respectively. The average dissipation ratios of vertical bedding coals are $0.17,0.25,0.26$, and 0.27 , and the average dissipation ratios of parallel bedding coals are $0.12,0.28,0.26$, and 0.27 , respectively. With the increase in confining pressure, the influence of bedding structure on dissipation ratio weakens.

(4) Based on the energy balance theory, a triaxial dynamic constitutive model of coal rock was established, where the DIF index and a comprehensive influence factor $K$ were introduced. The constitutive model considered the influence of confining pressure, strain rate, and bedding on the dynamic failure of coal rock and can better reflect the dynamic characteristics of coal rock. The model fits well to the stress-softening characteristics in the postpeak failure stage of coal rock, which is of great significance to the prevention of rock bursts.

\section{Data Availability}

The data used to support the findings of this study are available from the corresponding author upon request.

\section{Conflicts of Interest}

The authors declare that they have no conflicts of interest.

\section{Acknowledgments}

This research was financially supported by the Opening Fund of Key Laboratory of Deep Earth Science and Engineering Ministry of Education of Sichuan University (Grant no. DESE202003), the Key Scientific Research Fund of Xihua University (Grant no. Z17113), and the Graduate Innovation Fund of Xihua University (Grant no. YCJJ2020043).

\section{References}

[1] C. R. Ward, "Analysis, origin and significance of mineral matter in coal: an updated review," International Journal of Coal Geology, vol. 165, pp. 1-27, 2016.

[2] Y. Cai, D. Liu, Z. Pan, Y. Yao, and C. Li, "Mineral occurrence and its impact on fracture generation in selected qinshui basin coals: an experimental perspective," International Journal of Coal Geology, vol. 150-151, no. 151, pp. 35-50, 2015.

[3] X. Ou, X. Zhang, H. Feng, C. Zhang, and J. Yang, "Effect of the confining pressure on the dynamic compression properties of transversely isotropic rocks," Advances in Civil Engineering, vol. 2019, no. 4, 11 pages, Article ID 5239374, 2019.
[4] H. Song, Y. Jiang, D. Elsworth, Y. Zhao, J. Wang, and B. Liu, "Scale effects and strength anisotropy in coal," International Journal of Coal Geology, vol. 195, pp. 37-46, 2017.

[5] M. H. B. Nasseri, K. S. Rao, and T. Ramamurthy, "Anisotropic strength and deformational behavior of Himalayan schists," International Journal of Rock Mechanics and Mining Sciences, vol. 40, no. 1, pp. 3-23, 2003.

[6] H. Saroglou and G. Tsiambaos, "A modified Hoek-Brown failure criterion for anisotropic intact rock," International Journal of Rock Mechanics and Mining Sciences, vol. 45, no. 2, pp. 223-234, 2008.

[7] K. Liu, Q. Liu, Y. Zhu, and B. Liu, "Experimental study of coal considering directivity effect of bedding plane under Brazilian splitting and uniaxial compression," Chinese Journal of Rock Mechanics and Engineering, vol. 32, no. 2, pp. 308-316, 2013.

[8] X. Liu, X. Zhao, and J. Liu, "A study on the acoustic emission characteristics of the coal rock on different bedding direction," Computer Modelling and New Technologies, vol. 18, no. 5, pp. 308-313, 2014.

[9] X. Liu, F. Dai, R. Zhang, and J. Liu, "Static and dynamic uniaxial compression tests on coal rock considering the bedding directivity," Environmental Earth Sciences, vol. 73, no. 10, pp. 5933-5949, 2015.

[10] Q. B. Zhang and J. Zhao, "A review of dynamic experimental techniques and mechanical behaviour of rock materials," Rock Mechanics and Rock Engineering, vol. 47, no. 4, pp. 1411-1478, 2014.

[11] Y. Zhao, G.-F. Zhao, Y. Jiang, D. Elsworth, and Y. Huang, "Effects of bedding on the dynamic indirect tensile strength of coal: laboratory experiments and numerical simulation," International Journal of Coal Geology, vol. 132, pp. 81-93, 2014.

[12] X. J. Hao, "Study on bedding effect of bump tendency for hard coal," Coal Science and Technology, vol. 46, no. 5, pp. 1-7, 2018.

[13] C.-P. Lu, L.-M. Dou, X.-R. Wu, and Y.-S. Xie, "Case study of blast-induced shock wave propagation in coal and rock," International Journal of Rock Mechanics and Mining Sciences, vol. 47, no. 6, pp. 1046-1054, 2010.

[14] K. Duan, Y. Li, L. Wang, G. Zhao, and W. Wu, "Dynamic responses and failure modes of stratified sedimentary rocks," International Journal of Rock Mechanics and Mining Sciences, vol. 122, pp. 1-9, 2019.

[15] J. Qiu, D. Li, X. Li, and Z. Zhou, "Dynamic fracturing behavior of layered rock with different inclination angles in SHPB tests," Shock and Vibration, vol. 2017, pp. 1-12, 2017.

[16] X. Zhang, X. Ou, F. Gong, and J. Yang, "Effects of bedding on the dynamic compressive properties of low anisotropy slate," Rock Mechanics and Rock Engineering, vol. 52, no. 4, pp. 981-990, 2019.

[17] R. Wu, H. Li, X. Li, X. Xia, and L. Liu, "Experimental study and numerical simulation of the dynamic behavior of transversely isotropic phyllite," International Journal of Geomechanics, vol. 20, no. 8, pp. 1-16, 2020.

[18] S. Wen, C. Zhang, Y. Chang, and P. Hu, "Dynamic compression characteristics of layered rock mass of significant strength changes in adjacent layers," Journal of Rock Mechanics and Geotechnical Engineering, vol. 12, no. 2, pp. 353-365, 2020.

[19] S. Okubo, K. Fukui, and Q. Qingxin, "Uniaxial compression and tension tests of anthracite and loading rate dependence of peak strength," International Journal of Coal Geology, vol. 68, no. 3-4, pp. 196-204, 2006.

[20] F. Q. Gong, X. F. Si, X. B. Li, and S. Y. Wang, "Dynamic triaxial compression tests on sandstone at high strain rates 
and low confining pressures with split Hopkinson pressure bar," International Journal of Rock Mechanics and Mining Sciences, vol. 113, pp. 211-219, 2019.

[21] H.-b. Du, F. Dai, Y. Xu, Y. Liu, and H.-n. Xu, "Numerical investigation on the dynamic strength and failure behavior of rocks under hydrostatic confinement in SHPB testing," International Journal of Rock Mechanics and Mining Sciences, vol. 108, pp. 43-57, 2018.

[22] Z. Han, D. Li, T. Zhou, Q. Zhu, and P. G. Ranjith, "Experimental study of stress wave propagation and energy characteristics across rock specimens containing cemented mortar joint with various thicknesses," International Journal of Rock Mechanics and Mining Sciences, vol. 131, pp. 1-11, 2019.

[23] D. Li, Z. Han, Q. Zhu, Y. Zhang, and P. G. Ranjith, "Stress wave propagation and dynamic behavior of red sandstone with single bonded planar joint at various angles," International Journal of Rock Mechanics and Mining Sciences, vol. 117, pp. 162-170, 2019.

[24] G. Yang, J. Bi, X. Li, J. Liu, and Y. Feng, "SHPB testing and analysis of bedded shale under active confining pressure," Journal of Engineering, vol. 2020, Article ID 5034902, 2020.

[25] Z. C. Wang, Z. Zong, L. P Qiao, S. C. Li, and W. Li, "Elastoplastic constitutive model and parameter determination for transversely isotropic rocks," Chinese Journal of Geotechnical Engineering, vol. 40, no. 8, pp. 1457-1465, 2018.

[26] H. Li, T. Zhou, J. Deng, J. Yin, and J. Zhu, “An excess stress model for capturing rate-dependent compressive behavior of rock joint and its validation and applications," International Journal of Rock Mechanics and Mining Sciences, vol. 128, Article ID 104267, 2020.

[27] Z. M. Li, "Dynamic damage constitutive model of rock mass considering macro - and meso-level defects," Explosion and Shock Waves, vol. 35, no. 5, pp. 428-436, 2015.

[28] H. Y. Liu, S. R. Lv, L. M. Zhang, and X. P. Yuan, “A dynamic damage constitutive model for a rock mass with persistent joints," International Journal of Rock Mechanics and Mining Sciences, vol. 75, pp. 132-139, 2015.

[29] X. F. Ou, X. M. Zhang, C. Zhang, H. Feng, X. S. Zhou, and H. Zhao, "Study on bedding effect and damage constitutive model of slate under compressive dynamic loading," Chinese Journal of Rock Mechanics and Engineering, vol. 38, no. 10, pp. 3504-3511, 2019.

[30] Q. P. Sun and Z. Z. Zhang, "Study on the bedding effect and damage constitutive model of black shale under dynamic loading," Chinese Journal of Rock Mechanics and Engineering, vol. 38, pp. 1319-1331, 2019.

[31] Y. Li, Z. Zhu, B. Li, J. Deng, and H. Xie, "Study on the transmission and reflection of stress waves across joints," International Journal of Rock Mechanics and Mining Sciences, vol. 48, no. 3, pp. 364-371, 2011.

[32] R. Ulusay, The ISRM Suggested Methods for Rock Characterization, Testing and Monitoring: 2007-2014, Springer, New York, NW, USA, 2015.

[33] X. Li, Z. Zhou, Z. Ye et al., "Study of rock mechanical characteristics under coupled static and dynamic loads," Chinese Journal of Rock Mechanics and Engineering, vol. 27, no. 7, pp. 1387-1395, 2008.

[34] L. Song and S. S. Hu, "Two-wave and three-wave method in SHPB data processing," Explosion and Shock Waves, vol. 25, no. 7, pp. 368-373, 2005.

[35] L. Hong, "Size effect on strength and energy dissipation in fracture of rock under impact loads," Doctoral dissertation, Central South University, Changsha, China, 2008.
[36] H. B. Du and F. Dai, "Mechanical responses and failure mechanism of hydrostatically pressurized rocks under combined compression-shear impacting," International Journal of Mechanical Sciences, vol. 165, no. 9, pp. 1-15, 2020.

[37] H.-b. Du, F. Dai, Y. Liu, Y. Xu, and M.-d. Wei, "Dynamic response and failure mechanism of hydrostatically pressurized rocks subjected to high loading rate impacting," Soil Dynamics and Earthquake Engineering, vol. 129, no. 9, Article ID 105927, 2020.

[38] Z. Jia, H. Xie, R. Zhang et al., "Acoustic emission characteristics and damage evolution of coal at different depths under triaxial compression," Rock Mechanics and Rock Engineering, vol. 53, no. 5, pp. 2063-2076, 2020.

[39] Y. Q. Lu, X. H. Liu, J. Xie, Z. Q. He, and C. Li, “The energy evolution characteristics of coal under different dynamic strain rates and confining pressures," Thermal Science, vol. 23, no. 3, pp. 1409-1416, 2019.

[40] M. Cai, P. K. Kaiser, F. Suorineni, and K. Su, "A study on the dynamic behavior of the meuse/haute-marne argillite," Physics and Chemistry of the Earth, vol. 32, no. 8-14, pp. 907-916, 2007.

[41] X. H. Liu, R. Zhang, and J. F. Liu, "Experimental research on relationship between crushing size and energy consumption of coal rock under impact loading," Coal Technology, vol. 40, no. 6, pp. 45-49, 2014.

[42] Y. Luo, G. Wang, X. Li et al., "Analysis of energy dissipation and crack evolution law of sandstone under impact load," International Journal of Rock Mechanics and Mining Sciences, vol. 132, Article ID 104359, 2020.

[43] X. Si, F. Gong, X. Li, S. Wang, and S. Luo, "Dynamic mohr-coulomb and hoek-Brown strength criteria of sandstone at high strain rates," International Journal of Rock Mechanics and Mining Sciences, vol. 115, pp. 48-59, 2018.

[44] R. L. Shan, R. Q. Cheng, and W. J. Gao, "Study on dynamic constitutive modle of anthracite of yunjialing coal mine," Chinese Journal of Rock Mechanics and Engineering, vol. 25, no. 11, pp. 2258-2263, 2006.

[45] J. W. Zhou, Y. X. Liu, and Z. Y. Li, "Damage evolution of structured soil based on energy method," Chinese Journal of Geotechnical Engineering, vol. 35, no. 9, pp. 1689-1695, 2013.

[46] D. Ma, H. Duan, X. Li, Z. Li, Z. Zhou, and T. Li, "Effects of seepage-induced erosion on nonlinear hydraulic properties of broken red sandstones," Tunnelling and Underground Space Technology, vol. 91, no. 6, Article ID 102993, 2019.

[47] D. Ma, J. Zhang, H. Duan et al., "Reutilization of gangue wastes in underground backfilling mining: o," Chemosphere, vol. 264, Article ID 128400, 2021.

[48] H. X. He, W. M. Yan, and X. F. Li, "Research on unified uniaxial constitutive relationship of engineering materials based on SIR model," Chinese Journal of Computational Mechanics, vol. 31, no. 2, pp. 84-90, 2014.

[49] L. Yang, G. Wang, G.-F. Zhao, and L. Shen, “A rate - and pressure-dependent damage-plasticity constitutive model for rock," International Journal of Rock Mechanics and Mining Sciences, vol. 133, Article ID 104394, 2020.

[50] L. Y. Li, Z. J. Xu, H. Xie, Y. Ju, X. Ma, and Z. C. Han, “Failure experimental study on energy laws of rock under differential dynamic impact velocities," Meitan Xuebao/Journal of the China Coal Society, vol. 36, no. 12, pp. 2007-2011, 2011.

[51] C. Q. Zhang, J. J. Lu, J. Chen, H. Zhou, and F. J. Yang, "Discussion on rock burst proneness indexes and their relation," Rock and Soil Mechanics, vol. 38, no. 5, pp. 1397-1404, 2017. 